\title{
Building Block of Job Satisfaction in the Employees of Bank and Financial Institutions in Nepal
}

Bashu Neupane, M.Phil.

Lecturer, Tribhuvan University

Email: bashuneupane55@gmail.com

Nischal Risal, M.Phil.

Lecturer, Tribhuvan University

Email: nischal.risal@ncc.tu.edu.np

\begin{abstract}
The study aims at analyzing the determinants of job satisfaction in bank employees of Kathmandu valley, Nepal. The research has adopted analytical research design. The Exploratory Factor Analysis has been conducted to analyze the factor influencing job satisfaction of junior level bank employees in Kathmandu valley. The 31 usable sample sizes have been taken for the study purpose. The study found most significant factor as job security, years of experience, social status and financial status. The study concludes that the job security, experience and salary ad allowance are the building block of job satisfaction for junior level bank employees in Kathmandu valley.
\end{abstract}

Keywords: organizational factor, social factor, personal factor, financial factor, banks

\section{Introduction}

The satisfaction leads to performance, the performance leads to productivity, the productivity leads to gross domestic product, and the increase in GDP leads to increase in National Income. The major component of the financial system in Nepal is the bank and financial institutions. These institutions have great contribution in the socioeconomic development of the country. That's why the study attempts to analyze the factors influencing the job satisfaction in the employees of banks operating their business in Kathmandu valley.

Generally, job satisfaction of employees is given importance because of their various aspects of the job that makes highly attractive and lead to satisfaction of the job or lead to dissatisfaction (Sumitha \& Padmaja, 2017). In any organizational settings, job satisfaction of employees is an essential state to achieve its objectives. Today, the banking sector is witnessing sea changes due to the performance of their employees. The sublime performance of bank employees depends upon their job satisfaction. The nature of the bank work involves meeting the customer requirements, handling money transactions and maintenance of records. It is really hard to cater to the multifarious 


\section{THE BATUK : A Peer Reviewed Journal of Interdisciplinary Studies $\quad$ Vol. $6 \quad$ Issue No. 2 July 2020 ISSN 2392-4802}

demands of the customers. The bank employees should perform their services with a smile. The quality of banking service to be customers greatly depends upon the total efforts of the employees. Satisfied employees are the backbone for the successful functioning of the bank, its prosperity and progress. The building block of job satisfaction is recent research issue around the globe. Armstrong (2006) classified that job satisfaction has multi-dimensional facets consisting of attitudes towards salary, promotion, working experience, working environment and nature of work. Kaliski (2007) concluded that the human resource feels job stability, career growth and a comfortable work-life balance. The human resource is having satisfaction at a job as the work meets the expectations of the individual.

George and Jones (2008) explored that the collection of feeling and beliefs that human resources have their current job. Human resources also can have an attitude about various aspects of their job such kind of work they do, their co-workers, supervisors, subordinates and their pay. Aziri (2011) determined the efficiency and effectiveness of organizations are concerned with the employees and their job satisfaction is regarded as the main determinant. The new managerial paradigm of human resources should be treated and considered primarily as human beings that have their wants, needs, and personal desired is a good indicator for the importance of job satisfaction. Panghal (2013) concluded that the competitive environment, the critical thing is to know the views of human resource toward the job and measure the level of satisfaction with various aspects. Efficient human resource management and maintain higher job satisfaction of human resources that determine not only the performance of the bank but also affect the growth and performance of the entire economy.

Keith (2013) explained the factors influencing job satisfaction depend upon the nature of the work and working environment. Job satisfaction depends upon the four major factors. Similarly, an increase in the level of financial benefit, performance appraisal system, promotional strategies, training, and development program improves the overall satisfaction of human resources (Sharma, Dixit, Krishnappa, Sharma, Shukla, \& Jain, 2018). Vrinda and Jacob (2015) concluded that the satisfying event of human resources in the job, why they continue or leave the bank that also a determination of job satisfaction. Romel (2017) analyzed the job satisfaction of human resource as the major concerned for the success of the firm. Neupane (2019) concluded that job satisfaction means the positive feeling or attitude that employees have towards their job, which acts as a motivation to work. It is a combination of emotion, belief, feeling, sentiment, and other allied behavioral tendencies. 


\section{Research Methods}

The study has adopted the analytical research design. The population of the study is the entire workers of banks operating their businesses in Kathmandu valley. A purposive and convenience sampling methods have been used to collect the data. The self structured questionnaire has been used to collect the response from the respondents. Out of total 50 questionnaire distributed, the usable questionnaires have been confined to 31 responses. The factor analysis tools have been employed to analyze the job satisfaction of junior level employees in the banks. The Kaiser-Meyer- Olkin (KMO) Test and Bartlett's Test of Sphericity have been conducted to test the sampling adequacy of data that are to be used for factor analysis. The Exploratory Factor Analysis (EFA) has been conducted to determine the factor influencing job satisfaction in the bank employees. The SPSS software has been used to encode, decode, tabulate and analyze the data.

\section{Results and Discussion}

The data adequacy test was carried out on the primary data. Kaiser-Meyer-Oklin (KMO) Test was found to be 0.904 which is significant. The high values close to 1 generally indicated that a factor analysis might be useful for the given data. The test value of Bartlett's Test of Sphericity (approximate Chi-Square test) value 114.53 was also found significant at 5 percentage level of significance. This has indicated that data were adequate for factor analysis.

To achieve the presumed hypothesis of the study, the exploratory factor analysis (EFA) has been done to identify the factors underlying the construct "Job Satisfaction of Employees" and then to compute reliable composite scores corresponding to each factor. The data collected from a total of 31 junior employees of a bank on the nine declarative statements by asking employees to indicate their level of agreement to each statement on 1 to 5 scales where 1 corresponds to "Totally Disagree" and 5 corresponds to "Totally Agree".

The Principal Component method for extracting factors and Varimax method for obtaining rotated factor solution were used then after. Moreover, the Kaiser criterion (number of factors to be extracted equals to the number of Eigen value $>1$ ) was used to determine the number of factors. To support the number of factors the Scree Plot had been also used. For screening the variables, preliminary exploratory factor analysis (EFA) was carried out.

The preliminary analysis suggested excluding from the analysis because it had the low factor loading $(<0.5)$ to each communality. After excluding factors, the more factors were excluded to improve the communalities. 
4 THE BATUK : A Peer Reviewed Journal of Interdisciplinary Studies $\quad$ Vol. $6 \quad$ Issue No. 2 July 2020 ISSN 2392-4802

Table 1

Building Block of Job Satisfaction in Junior Level Bank Employees

\begin{tabular}{llllll}
\hline Factors & Rotated & Factor & Solution & & $\begin{array}{l}\text { Communalities } \\
\text { (Extraction) }\end{array}$ \\
\hline Job security & F1 & F2 & F3 & F4 & \\
Working hours & 0.887 & & & & 0.755 \\
Working condition & 0.794 & & & 0.833 \\
Age & 0.751 & & & & 0.726 \\
Salary and allowances & & 0.748 & & & 0.773 \\
Experience & 0.706 & & & 0.756 \\
Social status & 0.689 & & 0.787 \\
Relation with employees & & & 0.643 & & 0.829 \\
Economic conditions & & & 0.621 & & 0.709 \\
Technical facilities & & & & 0.619 & 0.846 \\
available & & & & 0.594 & 0.761 \\
Total variance explained by & & & & & \\
factors & 3.545 & 2.143 & 1.204 & 1.013 & 7.905 \\
\% Variance explained & 33.504 & 20.838 & 11.716 & 9.075 & 75.133 \\
Cronbach's alpha & 0.753 & 0.831 & 0.634 & 0.610 & 0.847 \\
\hline
\end{tabular}

Note: Factor loadings 0.4 have been suppressed.

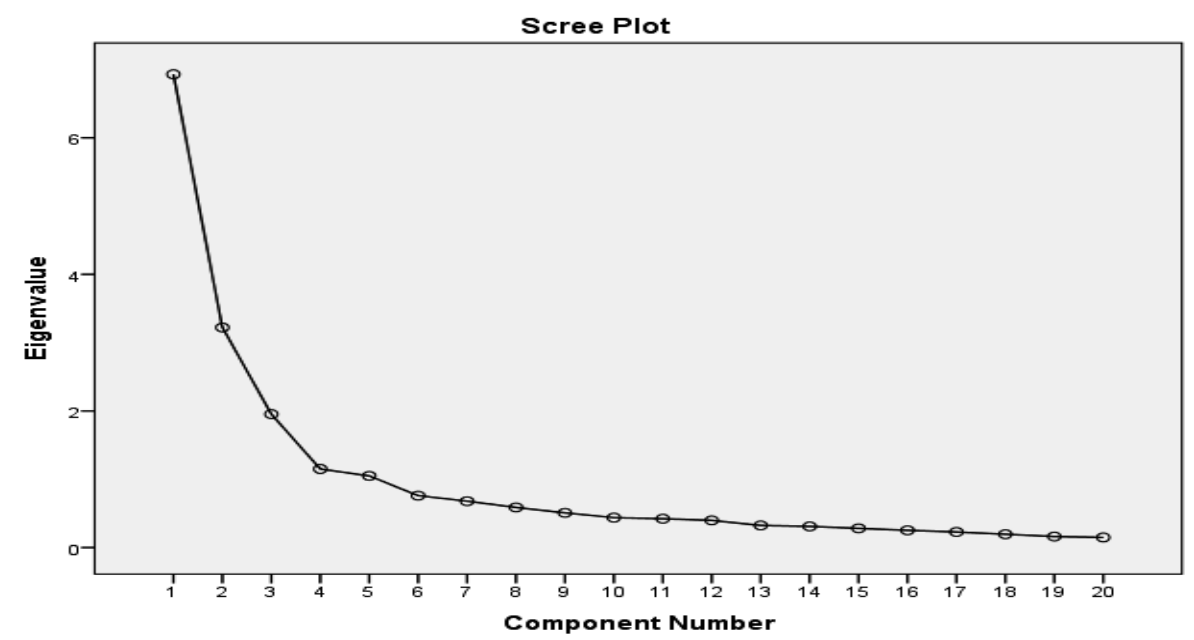

Figure 1. Factors influencing job satisfaction in junior level bank employees 
The reliability (alpha value) of the factors can be used to increase by excluding questions. As a result, it was decided to exclude the questions from the analysis. The main result began with checking the factorability of the correlation matrix of the retained ten items. Several well-recognized criteria of factorability were used and the main results of these criteria are presented below.

First, it was observed that a substantial number of correlation coefficients of the ten retained items were greater than 0.4. Second, the Kaiser-Meyer-Olkin (KMO) measure of sampling adequacy (MSA) was 0.904 which is above the commonly recommended value of 0.6 , and also the diagonal elements of the anti-image correlation matrix (or MSA of an individual item) were all over 0.5. The Bartlett's Test of Sphericity was significant $(\chi 2)=114.53, \mathrm{p}<0.001$. Finally, the commonality of each of the retained ten items was above 0.5 , further confirming that each item shared some common variance with other items. All the above results suggested that the currently available data on ten items is suitable in four factors for performing exploratory factor analysis. Comery and Lee (1992) concluded that the Eigen value of each factor is more than 1 and their extracted total variance of factor loading is more than 0.70 can be used in the further analysis of data. Hence, the Kaiser criterion (with four Eigen values) of the correlation matrix is greater than 1 extracted four factors in this study. The four factors F1, F2, F3 and F4 correspondingly explained or extracted $33.5 \%, 20.84 \%, 11.72 \%$ and $9.07 \%$ of the total variance, and altogether they extracted $75.13 \%$ of the total variance explained. As stated in Table 1, Figure 1 and Factor Analysis, the study found that job security as an organizational factor, which influences the job satisfaction of all junior-level bank employees. The experience or age is a personal factor, which determines the job satisfaction of junior level bank employees. The social status of the employees is a social factor, which influences job satisfaction. The economic condition is a financial factor, which influences the job satisfaction of the junior level bank employees.

\section{Conclusions}

The analysis of the results concluded that the working atmosphere should be conducive to enhance the employees' work efficiency. The experienced employees' voice should be considered to discuss in the staff meeting and given a role in decision-making. The salary and other allowances might influence to increase their financial condition of the junior level employees. Workload is the major burden for junior-level employees. The management took efforts to reduce the workload by the technical devices and tools. 
6 I THE BATUK : A Peer Reviewed Journal of Interdisciplinary Studies $\quad$ Vol. 6 Issue No. 2 July 2020 ISSN 2392-4802

\section{References}

Armstrong, M. (2006). A handbook of human resource management practice. London: Kogan Sage Publishing.

Aziri, B. (2011). Job satisfaction: A literature review. Management Research and Practice, 3(4), 77-86.

Comrey, A. L., \& Lee, H. B. (1992). A first course in factor analysis. New Jersey: Lawrence Erlbaum Associates Inc. Publisher.

George, J., \& Jones, R. (2008). Understanding and managing organizational behavior. New Jersey: Pearson/Prentice Hall.

Kaliski, B. S. (2007). Encyclopedia of business and finance. Detroit: Thompson Gale.

Keith, D. (2013). An assessment on job satisfaction of academic employees: a survey on Ethiopian private institutions of higher learning. International Journal of Research in Commerce and Management, 4(12), 26-39.

Neupane, B. (2019). A study on factors influencing the job satisfaction of bank employees in Nepal. NCC Journal, 4 (1), 9-15.

Panghal, S. (2013). Factors influencing job satisfaction of banking sector employees in India. International Journal of New Innovations in Engineering and Technology, 3.

Romel, M. (2017). Factors affecting job satisfaction in commercial banks. Journal of finance and Technology, 11, 54-62.

Sharma, A., Dixit, A. M., Krishnappa, K., Sharma, R., Shukla, S. K., \& Jain, P. K. (2018). A comparative study of sleep habits among medical and non-medical students in Saifai, Itawah. International journal community medical public health, 5(9), 1-6.

Sumitha, C., \& Padmaja, R. (2017). A study on job satisfaction of bank employees with special reference to Indian bank, Vellore city. International Journal of Research Granthaalayah, 5(7).

Vrinda, N., \& Jacob, A. (2015). The Impact of job satisfaction and performance, International Journal in Commerce, IT, and Social science, 2, 27-37. 